\title{
Antes da Copa, depois do Pan \\ O Rio de Janeiro na era dos megaeventos esportivos
}

Before the World Cup after the Pan American games

Rio de Janeiro in the era of sports mega-events

Edson Miagusko*

Resumo: O objetivo deste artigo é apresentar considerações sobre a realização dos megaeventos esportivos tomando por referência os processos de renovação e transformação urbanas no Rio de Janeiro. Nossa hipótese geral é que, por suas peculiaridades históricas e sociais, pela realização recente de grandes eventos internacionais e pela disposição dos "territórios da precariedade", o Rio de Janeiro se tornou um "laboratório" de experiências de intervenção urbana, redefinição de políticas públicas e tratamento da questão social, entrelaçando um conjunto diverso de políticas urbanas e sociais. Podemos afirmar que essa "era dos megaeventos esportivos" que se inaugurou no Rio de Janeiro com os Jogos Pan-americanos de 2007 e que se estenderá para além dos Jogos Olímpicos de 2016, já estruturam parte significativa das políticas na cidade, cujo princípio ordenador passa a ser o estado de emergência.

Palavras-chave: megaeventos; renovação urbana; copa do mundo; olimpíadas; jogos panamericanos

Abstract: The purpose of this paper is to present some considerations on the production of sports mega-events in Rio de Janeiro, in reference to processes of urban renewal and transformation that take place in this city. Our general hypothesis is that, by its historical and social peculiarities, the recent realization of major international events in the city and the allocation of "territories of precariousness", Rio de Janeiro became a relevant "laboratory" for experiences on urban intervention, redefinition of public policies and treatment of social issues, weaving a diverse set of urban and social policies. We can say that this "sports mega-events era", which started in 2007 with the Pan American Games in Rio de Janeiro and which will extend beyond the 2016 Olympic Games, already structures a significant part of the policies in the city, which ordering principle becomes the state of emergency.

Keywords: mega-events; urban renewal; world cup; olympic games; pan american games

* Professor Adjunto de Sociologia do Departamento de Ciências Sociais e do Programa de Pós-Graduação em Ciências Sociais da Universidade Federal Rural do Rio de Janeiro (UFRRJ) e pesquisador do Núcleo de Análise de Políticas Públicas (NAPP) da UFRRJ. <mia.eds@gmail.com>.

\begin{tabular}{|c|c|c|c|c|c|}
\hline Civitas & Porto Alegre & v. 12 & n. 2 & p. 395-408 & maio-ago. 2012 \\
\hline
\end{tabular}




\section{Introdução}

O objetivo deste texto é apresentar algumas considerações sobre a realização dos megaeventos esportivos, tomando por referência os processos de renovação e transformação urbanas no Rio de Janeiro, que tem levado a cidade a se tornar o lócus principal no país de eventos esportivos de grande porte.

Nossa hipótese geral é que, por suas peculiaridades históricas e sociais, pela realização recente de grandes eventos internacionais e pela disposição dos "territórios da precariedade", o Rio de Janeiro se tornou um "laboratório" de experiências de intervenção urbana, redefinição de políticas públicas e tratamento da questão social, entrelaçando um conjunto diverso de políticas urbanas e sociais.

Este texto faz parte de uma pesquisa mais ampla, ainda em processo, que visa compreender o papel dos megaeventos esportivos como estruturantes de um novo consenso sobre as políticas urbanas e sociais no Rio de Janeiro. Do nosso ponto de vista, os megaeventos esportivos estruturam um novo consenso de renovação urbana que no presente caso combinam políticas de segurança, valorização imobiliária e grandes eventos esportivos. Podemos afirmar que essa "era dos megaeventos esportivos" que se inaugurou no Rio de Janeiro com os Jogos Pan-americanos de 2007 e que se estenderá para além dos Jogos Olímpicos de 2016, já estruturam parte significativa das políticas na cidade, cujo princípio ordenador passa a ser o estado de emergência. ${ }^{1}$ Isso já tem impactos nas políticas urbanas, no tratamento da desigualdade social, nas políticas de segurança, políticas sociais e na conformação da cidade enquanto lugar socialmente determinado.

Nos limites deste artigo tratarei apenas de analisar os megaeventos esportivos a partir da especificidade desse fenômeno e do seu cruzamento com as políticas urbanas. Tratarei também de mapear conflitos recentes no processo de preparação da cidade para sediar esses megaeventos. Assim, este texto está dividido em duas partes. Na primeira, faço o levantamento

\footnotetext{
Há uma longa literatura que trata das noções de emergência e exceção, onde se destacam, sobretudo, os textos de Giorgio Agamben (Agamben, 2002 e 2004) que tem buscado compreender processos que tomam o estado de exceção como paradigma de governo dominante da política contemporânea (Oliveira e Rizek, 2007; Paulani, 2008). Nos limites desse artigo empregaremos o termo emergência no sentido de uma situação que exige uma ação diante de uma combinação inesperada de circunstâncias imprevistas (ou o que delas resulta) e que exigem ação imediata. Tem sido recorrente o argumento da emergência para estabelecer leis, suspender procedimentos no sentido de cumprir os prazos e atender as exigências estabelecidas pela Fifa (Fédération Internationale de Football Association) e pelo COI para a organização da Copa do Mundo de 2014 e as Olimpíadas de 2016.
} 
da literatura sobre os megaeventos buscando definir um conceito capaz de ressaltar a especificidade desses fenômenos ao mesmo tempo esportivos, econômicos e urbanos. Na segunda parte, tomo o período subseqüente ao Pan e que culmina com a escolha do Rio de Janeiro como sede das Olimpíadas de 2016 e busco mostrar como a realização desse megaevento que deixou como principal legado a vitória da candidatura do Rio de Janeiro como sede das Olimpíadas, não se repetiu nos demais aspectos onde os possíveis legados deveriam ser demonstrados.

\section{A cidade na era dos megaeventos esportivos}

Quando foi anunciada em Copenhague, em 2 de outubro de 2009, a escolha da cidade do Rio de Janeiro como sede das Olimpíadas de 2016, o resultado e a comemoração pareciam coroar com êxito um projeto iniciado há quase duas décadas, com duas candidaturas frustradas para sediar os Jogos de 2004 e 2012. A vitória teve seus contornos definidos com a realização dos Jogos Pan-americanos, cuja escolha fora recomendada pelo Comitê Olímpico Internacional (COI). Estes jogos demonstraram aos delegados do COI que o Rio de Janeiro tinha as condições necessárias para realização de um evento do porte olímpico.

A comemoração contagiou a delegação brasileira, tendo a frente o então Presidente da República Lula, presença considerada decisiva para a vitória da candidatura, pois expressava o consenso em todos os níveis de governo, algo inédito nos pleitos anteriores. Como demonstração desta unidade política também fazia parte da delegação o então presidente da Câmara, Michel Temer, que levara consigo um requisito adicional, algo que as outras cidades candidatas não haviam apresentado até então. O Congresso Nacional aprovara no dia anterior o Ato Olímpico, ${ }^{2}$ que garantia um conjunto de prerrogativas para o Comitê Olímpico Internacional, desde a dispensa da exigência de vistos para ingresso no território nacional para estrangeiros responsáveis pela organização dos Jogos, passando pela permissão de trabalho e isenção de qualquer taxa até a garantia do "controle, fiscalização e repressão de atos ilícitos que infringissem os direitos sobre os símbolos relacionados aos Jogos de 2016". O último item aprovado era a garantia mais importante, pois dizia

2 O Ato Olímpico é a Lei no 12.035 de 1 de outubro de 2009, aprovada por unanimidade pela Câmara dos Deputados e sancionada pelo vice-presidente José Alencar, no exercício da Presidência da República, que tem a finalidade no âmbito da administração pública federal, de assegurar garantias à candidatura da cidade do Rio de Janeiro para sediar os Jogos Olímpicos e Paraolímpicos de 2016 e de estabelecer "regras especiais" para a sua realização. A aprovação desta Lei estava condicionada à escolha da cidade como sede pelo Comitê Olímpico Internacional, o que foi confirmado no dia seguinte. 
respeito aos direitos de utilização dos símbolos negociados com os principais patrocinadores dos jogos, as empresas transnacionais que compram as cotas de patrocínio, além das grandes empresas de comunicação que negociam os direitos de transmissão.

Essa garantia fundamental, que apresentava um conjunto de salvaguardas para o Comitê Olímpico Internacional, era condição primeira para a realização dos Jogos nos países que pretendessem sediá-los. O Brasil saiu na frente dos concorrentes e a lei aprovada foi condicionada à escolha do Rio de Janeiro como cidade sede. A exceção estava embutida no próprio dispositivo da Lei que a tornava inócua em caso de derrota da candidatura e embutia a idéia de "regras especiais", garantindo ao Comitê Olímpico Internacional o atendimento das condições exigidas. Como veremos mais adiante, isso parece ser um traço de todos os dispositivos legais que foram aprovados antes e que vem sendo aprovados posteriormente como condição de realização dos próprios Jogos.

A candidatura do Rio chegou como forte concorrente em 2009 para sediar as Olimpíadas de 2016, dado as condições econômicas e políticas existentes e pelo fato da cidade ter passado no "vestibular olímpico" através dos Jogos Pan-americanos. Na primeira fase disputavam as seguintes cidades: Bakur (Afeganistão), Doha (Qatar), Chicago (EUA), Madri (Espanha), Praga (República Checa), Tóquio (Japão) e o próprio Rio de Janeiro (Brasil). Nesta primeira fase, Madri foi a mais votada, e para a segunda fase passaram Tóquio, Chicago e o Rio. Depois de mais uma votação, ficaram Madri e Rio para a última fase. No final, a candidatura brasileira triunfou por larga margem de votos em relação a sua concorrente espanhola.

Havia mais outras três candidaturas fortes - Chicago, Tóquio e Madri dentre as outras concorrentes. Os atributos destacados no dossiê destacavam três argumentos principais que garantiram a vitória ao Rio de Janeiro: o lugar do Brasil no mundo e seu peso econômico (único continente, a América do Sul, em que não ocorrera nenhuma Olimpíada e $10^{\mathrm{a}}$ economia mundial); o legado que poderia ser deixado pelos Jogos para a cidade; e como coroamento sua paisagem deslumbrante associada aos atributos do seu povo, sobretudo sua "mistura" e "felicidade". Em discurso considerado decisivo para a vitória do Rio de Janeiro, o Presidente Lula, destaca:

Com muito orgulho, represento, aqui, as esperanças e sonhos de mais de 190 milhões de brasileiros. Muitos nos acompanham pela TV neste momento, em telões nas areias de Copacabana, nas vitrines das lojas de São Paulo ou em pequenos televisores às margens do rio Amazonas. Estão todos unidos, torcendo pelo Rio de Janeiro. 
Somos um povo apaixonado pelo esporte, apaixonados pela vida. Olhando para os cinco aros do símbolo olímpico, vejo neles meu país. Um Brasil de homens e mulheres de todos os continentes: americanos, europeus, africanos, asiáticos, todos orgulhosos de suas origens e mais orgulhosos de se sentirem brasileiros.

Não só somos um povo misturado, mas um povo que gosta muito de ser misturado. É o que faz nossa identidade.

Definitivamente a cidade entrara na era dos megaeventos esportivos, iniciada com a realização dos Jogos Pan-americanos em 2007 e somada a outros eventos como a Copa do Mundo de 2014 que terá o Rio de Janeiro como palco da final. A vitória da candidatura olímpica só viera consolidar esta nova era dos megaeventos entrelaçados às demais políticas na cidade, notadamente, a política e a legislação urbanas.

Antes de seguir em frente, porém, é preciso responder duas questões que emergem desse novo cenário. A primeira é o que estamos considerando como megaevento e suas conexões com os processos de intervenção urbana e seus impactos sobre as diferentes camadas e grupos que habitam as cidades e quais as relações que nos permitem ver esse fenômeno para além de sua dimensão esportiva. Em segundo lugar, o processo que levou o Rio de Janeiro a se constituir como o principal palco e porque não dizer "laboratório" dos megaeventos no país.

Roche (2000) define megaeventos como:

[...] eventos de larga escala cultural (incluindo comerciais e esportivos) que tem uma característica dramática, apelo popular massivo e significância internacional. São tipicamente organizados por combinações variáveis de organizações internacionais não governamentais e podem ser ditos como importantes elementos nas versões 'oficiais' da cultura pública (Roche, 2000, p. 1).

Ele também aponta que os megaeventos são "ocasiões-chave onde as nações podem construir e apresentar imagens de si próprias para reconhecimento em relação a outras nações e aos olhos do mundo." Para o autor estas ocasiões-chave são acontecimentos onde "a tradição nacional e a comunidade, incluindo o passado, presente e futuro nacionais podem ser inventados e imaginados não apenas e somente pelos líderes e cidadãos do país de acolhimento, mas também por e pelos públicos de outras nações" (Roche, 2000, p. 6). Nesta definição, os Jogos Olímpicos são apenas a parte mais visível dos megaeventos, mas não são os únicos eventos que podem ser nomeados 
deste modo. Podemos incluir além dos eventos esportivos, grandes eventos que possibilitem a construção dessas imagens para o reconhecimento de uma determinada nação ou cidade aos olhos das outras, o que inclui também as grandes exposições no rol dos megaeventos.

Entre os megaeventos, aqueles de cunho esportivo assumiram lugar de proeminência. O principal de todos são os Jogos Olímpicos, o maior espetáculo esportivo em escala planetária e que movimentam maior quantidade de países participantes, atletas, patrocinadores e se constituem, nos dias atuais, num grande espetáculo televisivo e numa grande empresa comercial (Bourdieu, 1997). A Copa do Mundo de Futebol também tem assumido importância cada vez maior e a disputa para sediá-la se transformou em objeto de acirrada competição entre as cidades e nações do mundo. ${ }^{3}$ No rol dos megaeventos também devemos incluir eventos continentais/regionais que tenham essa mesma função. Assim, é possível incluir os Jogos Asiáticos, os Jogos Panamericanos, os Jogos Africanos, dentre outros, na denominação de megaeventos em âmbito regional/continental.

O fato é que esses megaeventos não podem ser tomados num sentido reduzido apenas como "grandes eventos esportivos". Pelo contrário, é possível considerá-los num sentido largo como exemplos paradigmáticos das novas formas de globalização nas sociedades modernas, que combinam mundialização e convergência de fatores. Neste caso, o exemplo mais paradigmático são os próprios Jogos Olímpicos que se converteram num fenômeno estratégico para diferentes setores sociais que abarcam uma gama variada de interesses: de empresas nacionais e transnacionais, governos em vários níveis, grandes conglomerados de comunicação e também esportistas.

De outro lado, os megaeventos também são utilizados como forma de atrair investimentos para as cidades e suas disputas passaram a ser cada vez

\footnotetext{
No momento que escrevo este texto ocorre a repercussão da disputa pelo comando da Fifa e as várias denúncias e acusações de que a sede da Copa do Mundo em 2022 foi negociada entre os representantes do Catar e o comitê executivo da entidade. Apesar das denúncias aparecerem nos dias em que ocorria a eleição, a candidatura única de Joseph Blatter foi reconduzida à presidência da entidade. As críticas mais duras vieram da Federação Inglesa de Futebol que também perdeu a sede da Copa para o Catar. Apesar da vitória de Blatter, os conflitos em relação ao comando da Fifa não se encerraram nos dias posteriores e podem se transformar numa disputa mais ampla. Nos dias da eleição, vazou para a imprensa que o ex-presidente Lula foi sondado pelos ingleses sobre sua disponibilidade em assumir o cargo de presidente da Fifa. Os ingleses voltaram a carga com duras críticas à Fifa, desta vez proferidas pelo próprio $1^{\underline{O}}$ Ministro inglês, David Cameron, que afirmou ao Parlamento inglês que "a reputação da Fifa está no nível mais baixo e, obviamente, a eleição com só um candidato foi uma farsa" (Folha de São Paulo, 9/06/2011).
} 
mais acirradas nos últimos anos, a partir da busca de projeção da imagem (Seixas, 2010) das cidades que disputam sua realização para o mundo. ${ }^{4}$

Não constitui novidade a utilização de grandes eventos como forma de atração de investimentos para as cidades que irão sediá-los. Mas a diferença fundamental é que esse recurso passou a ser mais utilizado com o acirramento da disputa entre cidades pela atração desses fluxos internacionais e por mudanças ocorridas nas políticas urbanas, a ponto de tornar a disputa das cidades como competição pela projeção de suas “marcas”. Harvey (2005), em texto clássico sobre o assunto, nomeia essa transformação do padrão do governo das cidades que passam a privilegiar a competição entre cidades pelos investimentos como "empresariamento urbano" ou "empreendedorismo urbano". Os fatores que levam a isso são múltiplos, mas fazem parte da crise fiscal enfrentada pelas economias capitalistas a partir da recessão de 1973 e que alteraram gradativamente o padrão de governança nas cidades mundiais.

A desindustrialização, o desemprego disseminado e aparentemente 'estrutural', a austeridade fiscal aos níveis tanto nacional quanto local, tudo isso ligado a uma tendência ascendente do neoconservadorismo e a um apelo muito mais forte (ainda que, frequentemente, mais na teoria que na prática) à racionalidade do mercado e à privatização, representam o pano de fundo para entender por que tantos governos urbanos, muitas vezes de crenças políticas diversas e dotados de poderes legais e políticos muito diferentes, adotaram todos uma direção muito parecida (Harvey, 2005, p. 168).

A situação conjuntural nos diferentes países pode ser diferente, mas as políticas urbanas passaram a ser cada vez mais parecidas quase como num moto-contínuo. Assim, à medida que as cidades passaram a disputar os recursos de modo cada vez mais intenso, os megaeventos passaram a ser mais valorizados e considerados como "janelas de oportunidades". O argumento é que a realização do megaevento abre um ciclo virtuoso em que as cidades recebem grandes investimentos, fazem intervenções em infraestrutura benéficas a todos, mas que em situações normais não teriam a mesma pressa e empenho de recursos e obtêm ganhos tangíveis no período da preparação à realização do megaevento (as obras, os equipamentos esportivos e públicos, o transporte urbano, etc.) e, no prazo maior, ganhos intangíveis da projeção

\footnotetext{
4 As experiências tem demonstrado que não há um legado garantido para as cidades e países que sediaram estes megaeventos. Há casos que são muito citados como sucesso como Barcelona e Los Angeles, mas há também fracassos e prejuízos para os países que sediaram os Jogos Olímpicos. O caso mais recente de fracasso é a situação da Grécia. Há informações que as dívidas acarretadas pelos Jogos Olímpicos em Atenas agravaram ainda mais a crise financeira do referido país (Rúbio, 2005; Boykoff, 2011).
} 
de imagem para o mundo e suas consequências em termos de turismo, investimentos e publicidade. ${ }^{5}$

Mas se é fato que a produção desse consenso que envolve a organização de megaeventos e sua circulação, a disputa entre as cidades por sua realização e a forma de governo urbano se assemelhando cada vez mais em situações distintas, o próprio arranjo que organiza uma coalizão de interesses capazes de levar à frente sua realização parece ser muito distinto entre as diferentes cidades. A questão fundamental a responder é como esse consenso se organiza e por que num dado momento essa coalizão de forças se aglutina e quais as condições que se apresentam para que isso aconteça.

No caso do Rio de Janeiro, a escolha da cidade como sede das Olimpíadas se tornou realidade somente depois da terceira candidatura que não era aquela que despertara maior comoção popular no seu início. A candidatura de 2004 envolvera muito mais a cidade, mesmo que as condições reais de sua vitória fossem quase nulas, conforme declaração do presidente do Comitê Olímpico Brasileiro (COB). ${ }^{6}$ Além disso, o prefeito empreendedor que concebeu sua realização não era o atual ocupante do cargo. Ao contrário, a coalizão que governara a cidade por 16 anos e que de algum modo tinha o projeto olímpico como estratégico de sua concepção de cidade havia sido derrotada nas eleições anteriores e fora substituída por uma nova coalizão, mesmo que de certo modo o atual prefeito tivesse seu nascimento político no governo do antigo. ${ }^{7}$

Um momento chave para compreender esse processo que leva à escolha da cidade como sede olímpica são os Jogos Pan-americanos de 2007. A realização do Pan parece ter sido fundamental para a vitória do Rio de Janeiro como sede olímpica. Mas, o Pan deixou um paradigma de intervenção urbana,

5 Mesmo a história da realização das Olimpíadas não se relaciona como uma constância nos vultosos patrocínios sobre os direitos da marca. Seu ponto de ruptura se dá nas Olimpíadas de Los Angeles de 1984 em que as parcerias público-privadas se tornam o modelo de financiamento dos Jogos, o que passa a refazer toda a economia do próprio esporte.

6 O presidente do Comitê Olímpico Brasileiro (COB) Carlos Nuzman fez a seguinte afirmação em entrevista à Revista Isto É, em 28/07/2003: "A Rio 2004 foi uma candidatura política. O próprio Comitê Olímpico Internacional mudou o sistema depois, obrigando os comitês olímpicos nacionais a estarem na linha de frente das candidaturas. Naquela ocasião, o COB meramente emprestou o nome e deu apoio. Não acreditava na vitória naquela época".

7 O atual prefeito do Rio de Janeiro, Eduardo Paes foi eleito em 2008 por uma coalizão de partidos encabeçada pelo PMDB (Partido do Movimento Democrático Brasileiro), apoiada pelo governador do Estado do Rio de Janeiro, Sérgio Cabral, e que derrotou Fernando Gabeira, candidato do PV (Partido Verde), à época apoiado pelo prefeito César Maia. Eduardo Paes, no entanto, iniciou sua carreira política como um dos braços direitos do prefeito César Maia, filiado ao PV e depois ingressante no DEM - Democratas (antigo PFL - Partido da Frente Liberal). Na prefeitura foi subprefeito da Barra da Tijuca e Jacarepaguá. Antes de ingressar no PMDB foi do PTB (Partido Trabalhista Brasileiro) e deputado federal pelo PSDB (Partido da Social Democracia Brasileira). 
que pode ser compreendido a partir da legislação urbana, do consenso político, na forma de tratamento das parcelas mais vulneráveis da população e no discurso de emergência que parece se repetir nesse momento. Assim, analisar os legados do Pan pode nos mostrar um tipo de ação cujos desdobramentos não se encerram num único governo e parecem se perpetuar num novo paradigma de intervenção urbana.

\section{Depois do Pan e antes da Copa: os legados e a cidade}

A compreensão sobre megaeventos ultrapassou os setores relacionados aos estudos esportivos a partir dos impactos dos Jogos Pan-americanos em 2007. De algum modo, esse campo de estudo só poderia ter relevância conforme ocorresse o ingresso do país e da cidade do Rio de Janeiro no circuito dos grandes eventos. Assim, é possível perceber o aparecimento de estudos que buscam descrever os impactos dos Jogos Pan-americanos em 2007 sobre a cidade e os legados no momento seguinte (Benedicto, 2008; Mascarenhas, 2007; Omena, 2011; Bienenstein, 2011). A maioria desses estudos mostra que há dois níveis de questões que devem ser destacados: o primeiro é a concepção de políticas urbanas definidas a partir do modelo do planejamento estratégico, do marketing urbano e do entrelaçamento entre público e privado. Neste caso o Estado é somente um dos atores e nem sempre no interior dessa coalizão de forças é o agente principal. Seu peso, suas atribuições e a forma de intervenção dependem do campo de forças que se aglutina e do consenso político que se sedimenta num dado momento. O segundo, é que em termos de legados os estudos mostram que várias metas traçadas antes da realização dos Jogos não foram cumpridas com problemas de várias ordens, desde remoções, não cumprimento das metas sociais até subutilização ou não utilização de equipamentos esportivos.

A realização dos Jogos Pan-americanos, apesar das críticas, foi um momento chave para garantir a escolha da cidade e para desencadear os processos de renovação urbana capazes de demonstrar as condições de sediar as Olimpíadas. É fato, como destaca Vainer (2011), que a implementação da Copa do Mundo e das Olimpíadas não ocorre por acaso e é oriunda do projeto que se torna hegemônico na década de 1990 a partir da coalizão encabeçada pelo prefeito César Maia. Mas sua consecução só ganhará viabilidade com a realização do Pan e sob a direção de um novo campo de forças políticas no Rio de Janeiro, que juntará num mesmo plano os governos da cidade, do Estado e do país. É como se, ironicamente, a possibilidade de realização do projeto em toda a sua plenitude só fosse possível sob a égide de novos agentes, capazes de selar o consenso de maneira mais ampla e com menos conflitos políticos 
secundários. E para isso jogariam papel decisivo as garantias do governo federal, tomadas pelo COI como fundamentais para a escolha da cidade sede e a ampla unidade em torno da realização dos Jogos Olímpicos. ${ }^{8}$

Do ponto de vista dos processos socioespaciais, o Pan inaugurou um conjunto de intervenções de renovação urbana, construção de equipamentos esportivos e, sobretudo, abriu a possibilidade da aprovação de uma nova legislação que legasse instrumentos urbanísticos necessários para intervenções de grande porte através da perspectiva das parcerias público privadas.

O grande legado dos Jogos Pan-americanos foi demonstrar aos delegados do Comitê Olímpico Internacional (COI) a capacidade da cidade em organizar eventos esportivos de porte significativo. Isso foi decisivo para conferir melhores condições para que o Rio de Janeiro pudesse vencer o processo de escolha da cidade sede. Este foi o principal legado, destacado pelos dirigentes esportivos e pelos governantes no sentido de mostrar que sem os Jogos Pan-americanos em 2007 haveria maiores dificuldades para o sucesso da candidatura olímpica. Assim, o argumento apresentado recorre a uma fuga para frente sobre os possíveis legados do Pan, destacando não as conseqüências visíveis do projeto, mas ressaltando, sobretudo, as possibilidades abertas pelo sucesso da candidatura olímpica que ainda estão por vir. O ciclo virtuoso só foi aberto e os investimentos na cidade nos próximos anos trarão legados ainda mais duradouros e significativos em que todos ganharão. Esta elevação das expectativas reduz qualquer possibilidade de conflito e dissenso e transforma o estado de emergência no paradigma de ação dos governos e de julgamento das suas ações.

Porém, os chamados "legados" do Pan apresentam mais controvérsias, se deixarmos de lado o que virá e nos concentrarmos naquilo que já veio. A primeira delas tem a ver com o custo total da competição. Em 2002, a previsão era de R \$ 410 milhões e terminou em R \$ 3,7 bilhões, ou seja, nove vezes mais que o valor estipulado inicialmente. Uma das obras em que o orçamento estourou foi na construção do Estádio João Havelange, o Engenhão, que custou $\mathrm{R} \$ 74$ milhões a mais que o valor anunciado inicialmente, de $\mathrm{R} \$ 380$ milhões. Segundo o relatório do Tribunal de Contas da União foram detectados danos de $\mathrm{R} \$ 884,7$ mil em superfaturamentos e serviços não executados.

\footnotetext{
8 Carlos Artur Nuzman, presidente do COB, destaca esse elemento como decisivo para a vitória da candidatura. No momento anterior à escolha, ele apresentava essa unidade como diferencial em relação a outras cidades: "Eu desafio as concorrentes a apresentarem a mesma quantidade de garantias que o Rio apresentou. Isto só foi possível devido a uma inédita parceria entre todos os níveis de governo" (O Globo, 13/02/2009, "Comitê Rio 2016 divulga seu projeto olímpico").
} 
O segundo aspecto se relaciona às grandes obras e seus impactos. Podemos mapear cinco conflitos em torno das obras e equipamentos do Pan, a saber: a construção da Vila do Pan e complexo do Autódromo; o estádio de futebol João Havelange, o Engenhão; o caso da Marina da Glória; o estádio de Remo da Lagoa; as medidas de segurança que motivaram operações no Complexo do Alemão (Benedicto, 2008). Dessas intervenções é possível inferir o problema das remoções de comunidades socialmente vulneráveis, da concentração de equipamentos na área da Barra da Tijuca, de especulação imobiliária e conflitos em torno da conservação urbana e do patrimônio e de medidas de segurança e de denúncia de violação dos direitos humanos em comunidades pobres. Apesar do discurso voltado a todos os moradores da cidade, apresentando uma sinergia que trará benefício a todos, do ponto de vista territorial houve uma concentração dos equipamentos na Barra da Tijuca, algo que se repete nas principais intervenções previstas para as Olimpíadas de 2016.

O terceiro aspecto, menos visível, é mais preocupante. Há um conjunto de instrumentos, dispositivos e leis que tem suspendido outros dispositivos legais e que são aprovados sob o argumento da emergência. No âmbito federal, há o Ato Olímpico e uma MP que criou a Autoridade Olímpica (APO). Além disso, tramita no Congresso outra MP 521 que institui o Regime Diferenciado de Contratações e estabelece mecanismos legais que suspendem a Lei de Licitações (8.666/93), que visa criar "regras especiais" para as licitações tanto na Copa quanto nas Olimpíadas. Este dispositivo tem sido muito criticado pela imprensa, órgãos de controle e demais setores da sociedade que apontam uma violação da lei de licitações e falta de transparência nos processos licitatórios, com o sigilo prévio sobre o orçamento, centralização no COI e na Fifa dos aditamentos de contrato. O governo alega que busca aperfeiçoar a lei de licitações e evitar a formação de cartéis na definição dos preços no setor da construção civil e, para isso, recorre à legislação mais moderna, tendo como inspiração a legislação inglesa. Mas, convém apontar que a alteração da lei de licitações a partir de uma medida provisória não deveria ser feita sob o signo da emergência e deveria ser mais debatida, dado suas implicações em termos de transparência e utilização de recursos públicos. Pois de algum modo, há um movimento de mão dupla: o atraso das obras causa a necessidade de aprovação de instrumentos que permitam instaurar a suspensão das leis e dos controles existentes e sua substituição por mecanismos cada vez mais flexíveis que permitam desregulamentar, tornar mais flexíveis e até mesmo suspender os dispositivos legais existentes. O paradigma de legislação de patrocínios cuja aprovação é exigida pelo COI parece se desdobrar deste modo em outras 
esferas tornando a regulação da cidade ou sua "desregulação" num estado de emergência olímpica à semelhança de uma emergência econômica que propicia aos governos desencadearem um conjunto de medidas para responder a situações de crise financeira (Paulani, 2008).

No âmbito municipal há três pacotes de leis acompanhados de alguns decretos como o Projeto Porto Maravilha (1999), o Plano de Estruturação das Vargens (1999) e o Pacote Olímpico (Oliveira, 2011). A aprovação dessas leis mostra um traço comum: "regras especiais" e suspensão dos dispositivos legais anteriores que na prática tem tornado o Rio de Janeiro uma "cidade da exceção" (Vainer, 2011).

Assim, o que transparece é que o principal legado dos Jogos Panamericanos foi ter qualificado a candidatura olímpica e garantido a vitória do Rio de Janeiro como cidade sede. Em relação ao legado urbanístico e social há uma controvérsia muito maior sobre seus resultados não apenas do ponto de vista da utilização dos recursos, da construção dos equipamentos, mas, sobretudo, do conjunto de intervenções urbanísticas relacionadas às populações socialmente mais vulneráveis e à legislação urbana que tem o paradigma da emergência e da suspensão de determinados dispositivos legais como princípio ordenador.

\section{Momento atual: para onde vai a cidade?}

A literatura que estudou o Pan tem ressaltado um balanço problemático acerca dos legados deixados pelos Jogos. E com o processo de preparação dos megaeventos que ocorrerão na cidade, nos próximos anos, várias situações reaparecem e indicam uma persistência nos problemas já citados. Com o processo de preparação dos megaeventos e com o aporte de recursos que advém decorrente das obras necessárias para receber a Copa do Mundo e as Olimpíadas, a atenção do público parece se concentrar apenas nos benefícios para a cidade. Mas, o que parece acontecer é que a distribuição dos benefícios não acontece de maneira igual nem pelos diferentes setores sociais e nem do ponto de vista de sua distribuição espacial, com a concentração de recursos e investimentos em determinados lugares da cidade.

Em razão disso inúmeras redes e movimentos tem se articulado para acompanhar a realização dos megaeventos. Estas articulações tem como características principais sua organização na forma de redes que combinam movimentos sociais, organizações não-governamentais, instituições acadêmicas, órgãos de controle públicos e outras organização da sociedade civil.

A principal rede que tem se articulado no sentido de acompanhamento da sociedade civil e dos setores populares da Copa do Mundo e das Olimpía- 
das é o Comitê Popular Rio 2016. Este Comitê surge a partir da experiência de acompanhamento dos Jogos Pan-americanos de 2007 e se amplia depois de sua realização a partir de sua estruturação com outras organizações e entidades da sociedade civil. A análise destas articulações, contudo, será assunto para outro artigo.

Assim, o presente trabalho buscou apresentar algumas anotações sobre os megaeventos esportivos no momento posterior à realização dos Jogos Pan-americanos de 2007, considerados como fundamentais para a vitória do Rio de Janeiro como sede olímpica. Consideramos que os megaeventos esportivos já fazem parte de um novo consenso sobre as políticas urbanas. Esta era dos megaeventos esportivos é ditada por um estado de emergência olímpica que passa a ditar não apenas as políticas urbanas, mas incide no conjunto das demais políticas que tem a cidade como seu espaço.

\section{Referências}

AGAMBEN, Giorgio. Estado de exceção. São Paulo: Boitempo, 2004. 2002. . Homo Sacer: o poder soberano e a vida nua I. Belo Horizonte: Ed. UFMG,

ARANTES, Otília; VAINER, Carlos; MARICATO, Ermínia. A cidade do pensamento único - desmanchando consensos. Petrópolis: Vozes, 2000.

BENEDICTO, Danielle Barros de Moura. Desafiando o coro dos contentes: vozes dissonantes no processo de implementação dos Jogos Pan-americanos, Rio 2007. Dissertação em Planejamento Urbano e Regional, Rio de Janeiro, 2008.

BIENENSTEIN, Glauco. O espetáculo na cidade e a cidade no espetáculo: grandes projetos, megaeventos e outras histórias. XIV Encontro Nacional da Anpur. Rio de Janeiro: Anpur, 2011.

BOURDIEU, Pierre. Sobre a televisão. Rio de Janeiro: Jorge Zahar Editor, 1997.

BOYKOFF, Jules. The Anti-Olympics. New Left Review, London, jan./fev. 2011.

HARVEY, David. A produção capitalista do espaço. São Paulo: Annablume, 2005.

MASCARENHAS, Gilmar. Mega-eventos esportivos, desenvolvimento urbano e cidadania: uma análise da gestão da cidade do Rio de Janeiro por ocasião dos Jogos Pan-americanos de 2007. Scripta Nova: Revista Eletrônica de Geografia y Ciencias Sociales. Barcelona: Universidad de Barcelona, ago. 2007.

MELLO, Erick Silva Omena; GAFFNEY, Christopher. Mega-eventos esportivos no Brasil: uma perspectiva sobre futuras transformações e conflitos urbanos. Disponível em: <http:www.fase.org.br/v2/pagina.php?id=3462>. Acesso em 20 ago. 2011.

OLIVEIRA, Francisco de; RIZEK, Cibele Saliba. A era da indeterminação. São Paulo: Boitempo, 2007. 
OLIVEIRA, Nelma Gusmão de. Força de lei: rupturas e realinhamentos institucionais na busca do "sonho olímpico" carioca. XIV Encontro Nacional da Anpur. Rio de Janeiro: Anpur, 2011.

OMENA, Erick. Desafios no caminho para o "Rio 2016": o que nos dizem as experiências anteriores? Revista eletrônica e-metropolis (Observatório das Metrópoles/ Ippur), p. 14-25, mar. 2011.

PAULANI, Leda. Brasil Delivery. São Paulo: Boitempo, 2008.

RAEDER, Sávio. Rio 2016 e o urbanismo olímpico. Biblio 3W-Revista Bibliográfica de Geografia y Ciencias Sociales, 05 de novembro de 2010.

ROCHE, Maurice. Mega-events and modernity: Olympics and expos in the growth of global culture. London: Routledge, 2000.

RUBIO, Katia. Os Jogos Olímpicos e a transformação das cidades: os custos sociais de um megaevento. Scripta Nova: Revista Eletrónica de Geografia y Ciencias Sociales, Barcelona: Universidad de Barcelona, v. IX, ago. 2005.

SEIXAS, João. Imagética social, política econômica e governança urbana. Revista eletrônica e-metropolis (Observatório das Metrópoles/Ippur), n. 2, set. 2010.

VAINER, Carlos. Cidade de exceção: reflexões a partir do Rio de Janeiro. XIV Encontro Nacional da Anpur. Rio de Janeiro: Anpur, 2011.

Data de recebimento: $26 / 08 / 2011$

Data de aprovação: 20/11/2011 